\title{
Unusual megaloblastic anaemia with multinucleate erythroblasts: Two cases with septicaemia and acute renal failure
}

\author{
M. SAARY ${ }^{1}$, J. G. P. SISSONS, W. A. DAVIES ${ }^{2}$, AND A. V. HOFFBRAND ${ }^{3}$ \\ From the Department of Haematology and Nephrology, The Royal Postgraduate Medical School, Du Cane \\ Road, London
}

SYNOPSIS The case histories and blood pictures of two patients who had cardiac lesions, septicaemia, and renal failure, and terminally developed a leucoerythroblastic anaemia with megaloblastic features associated with multinucleate erythroblasts, are described. Though folate deficiency may have made a minor contribution to the blood abnormalities, it is considered that some other disturbance in erythropoiesis was responsible for the bizarre blood and bone marrow changes in these patients. Similar cases reported in the earlier literature are reviewed.

Megaloblastic anaemia is usually due to deficiency of vitamin $B_{12}$ or folate. A morphologically similar anaemia refractory to vitamin $B_{12}$ and folic acid therapy may also be caused by other disturbances of DNA synthesis in the bone marrow, and megaloblastosis has been described in patients with erythroleukaemia and acquired sideroblastic anaemia, in patients receiving drugs which interfere with DNA synthesis, eg, cytosine arabinoside and hydroxyurea, as well as in certain congenital disorders including congenital dyserythropoietic anaemia, the Lesch-Nyhan syndrome and orotic aciduria (Chanarin, 1969; Hoffbrand, 1971).

We have recently observed two patients who, during their terminal illness, developed a leucoerythroblastic anaemia in which megaloblasts with multiple and multilobulated nuclei were outstanding features. Giant forms were also present in one of the cases. The cause of the acquired megaloblastic anaemia in these patients was obscure, but as their clinical syndromes and haematological findings were similar, it seems likely that the aetiology of the megaloblastosis and of the other dyserythropoietic features were also similar. This paper describes the

\footnotetext{
'Present address: Department of Haematology, St Bartholomew's Hospital, London EC.

'Present address: Wexham Park Hospital

'Present Address: The Royal Free Hospital, Pond Street, Hampstead, London NW3 2QG, and address for reprints.

Received for publication 3 December 1974.
}

clinical and haematological course of these two patients and illustrates their blood and bone marrow appearances.

\section{Case 1}

This patient, W. W., a man aged 52, had a closed mitral valvotomy at Hammersmith Hospital in 1965 for rheumatic mitral valve stenosis. The operation resulted in symptomatic improvement but left some mitral regurgitation. He remained well for five years but then developed progressive exertional dyspnoea which led to his readmission on 9 November 1972 for mitral valve replacement. On examination there were signs of mitral regurgitation and stenosis, with controlled atrial fibrillation and an elevated jugular venous pressure, but no other abnormal physical findings. Investigations showed a normal blood urea and electrolytes.

The mitral valve was replaced on 13 November with a Starr-Edwards prosthesis. The total period of cardiopulmonary bypass was 114 minutes during which only $80 \mathrm{ml}$ of dark red urine was passed. Postoperatively his cardiac state was satisfactory and, although initially he was oliguric, the urine output improved with frusemide therapy $(250 \mathrm{mg}$ intravenously daily). Blood urea rose to $220 \mathrm{mg} /$ $100 \mathrm{ml}$ on 18 November, presumably due to acute tubular necrosis following hypotension and haemolysis during bypass; the same day he had a transient cardiac arrest and then developed acute pulmonary 
oedema. He was put on intermittent positive pressure ventilation (IPPR) and peritoneal dialysis (PD) was started. He had improved 24 hours later and IPPR was stopped for a few hours but subsequently restarted.

By 19 November, he was febrile and had developed a Pseudomonas aeruginosa chest infection, which was treated with gentamicin ( $40 \mathrm{mg}$ bd intramuscularly) and carbenicillin ( $5 \mathrm{~g}$ four-hourly intravenously) the doses adjusted for his renal failure. Although he had received sedative and muscle relaxant drugs only once, on restarting IPPR he remained comatose and unresponsive with flaccid limbs and hyporeflexia but with no focal neurological signs. Peritoneal dialysis, which controlled the blood urea at about $200 \mathrm{mg} / 100 \mathrm{ml}$, and IPPR were continued but despite antibiotic treatment, the high fever persisted: the neurological signs did not change, no cause being found for the impaired consciousness. Folic acid, $10 \mathrm{mg}$ intravenously, was given on 23 November. On 24 November he developed cardiac asystole and died.

At necropsy the heart showed a recent myocardial infarct and left atrial mural thrombus but the prosthetic valve appeared normal. There was patchy bronchopneumonia and an area of lung infarction which was infected with Aspergillus. The kidneys showed acute tubular necrosis and there was some splenic infarction. There was no evidence of extramedullary haemopoiesis in the liver or spleen. The brain could not be examined.

\section{HAEMATOLOGICAL FINDINGS}

Preoperatively, the haemoglobin was $14.3 \mathrm{~g} / 100 \mathrm{ml}$, MCV $90 \mathrm{fl}$, WBC $10400 / \mu \mathrm{l}$, platelets normal, and the blood film was normal. On the second postoperative day, normoblasts appeared in the peripheral blood and the neutrophil count began to rise (fig 1). On the sixth day oval polychromatic macrocytes and a few megaloblasts, some containing 3-4 HowellHolly bodies, were apparent in the peripheral blood (figs 2a, b, and c). Some of the megaloblasts showed an opaque blue-staining cytoplasm with a peripheral dense zone and perinuclear halo. Pyknotic erythroblasts, some of which featured karyorrhexis and Howell-Jolly bodies, and myelocytes and promyelocytes were also present. On the tenth postoperative day the haemoglobin concentration had fallen to $9 \cdot 3 \mathrm{~g} / 100 \mathrm{ml}$ and the reticulocyte count was $1.2 \%$. The circulating erythroblasts were now all megaloblastic, though the majority of red cells were still normocytic with only occasional macrocytes. Serum folate assay at this point gave readings below the blank of the assay due to inhibition of the growth of $L$. casei by antibiotics in the serum, shown by adding the serum to known standards. The serum

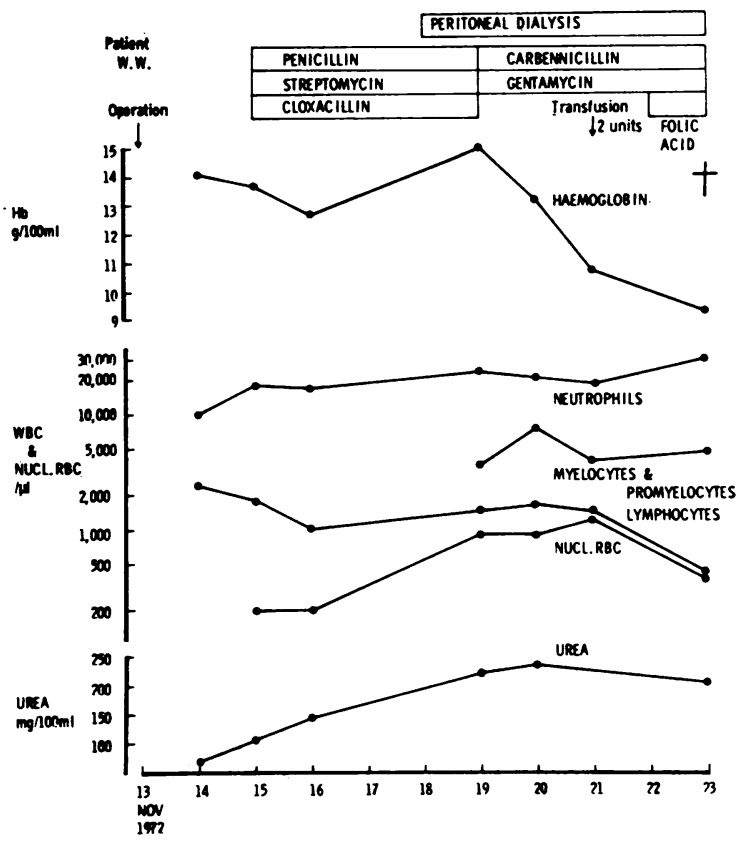

Fig 1 Haematology chart of patient W.W. (case 1) in the terminal phase of his illness.

vitamin $\mathrm{B}_{12}$ level measured by Euglena gracilis was normal $(624 \mathrm{pg} / \mathrm{ml})$. The leukaemoid white cell picture persisted and now included occasional blast cells. A few neutrophils had vacuolated cytoplasm but giant metamyelocytes and hypersegmented polymorphs were absent.

Bone marrow was aspirated from the posterior iliac crest on the eleventh postoperative day (one day before death). This was normocellular but erythropoiesis was frankly megaloblastic with many multinucleate cells, a proportion showing up to five nuclei, some with incomplete division (figs $2 \mathrm{~d}$ and $2 \mathrm{e}$ ), and some showing internuclear strands (fig 2f). A few bizarre giant cells were seen (fig $2 \mathrm{~g}$ ) which were thought to be abnormal multinucleate megaloblasts ('gigantoblasts') rather than megakaryocytes which were normal in number and morphology. Periodic acid-Schiff-positive material, present in the megakaryocytes, was absent from these giant cells. Abnormal mitotic figures, some tripolar, were observed in well haemoglobinized as well as in more primitive cells. Granulopoiesis featured a few giant metamyelocytes and vacuolated neutrophils (fig 2e). Erythrophagocytosis was not present. Iron was present in stores and erythroblasts. No abnormal sideroblasts were seen. 


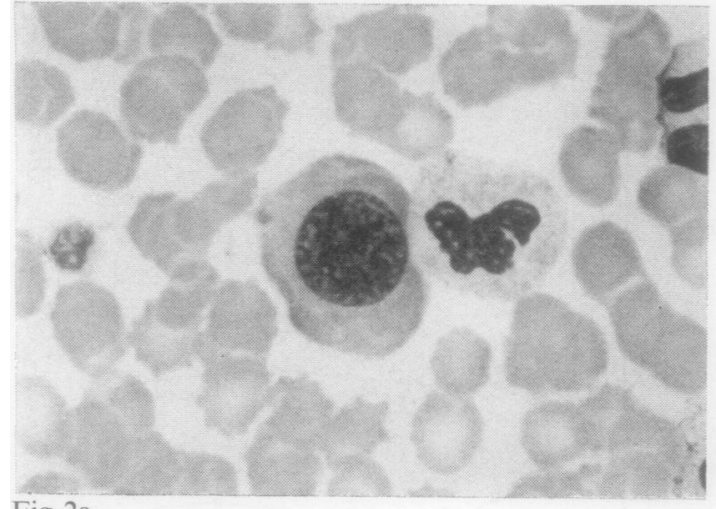

Fig 2a

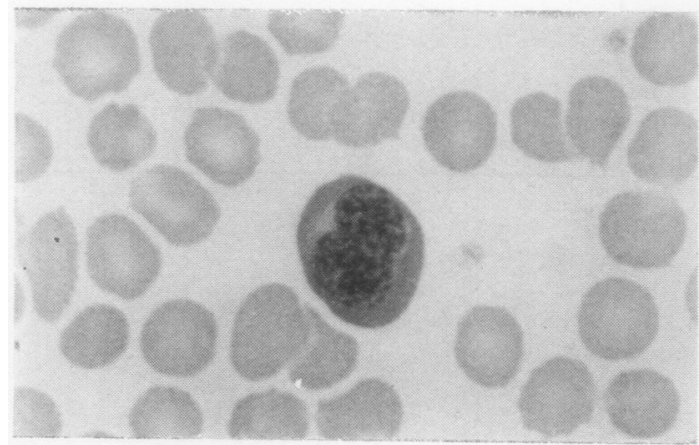

Fig 2b

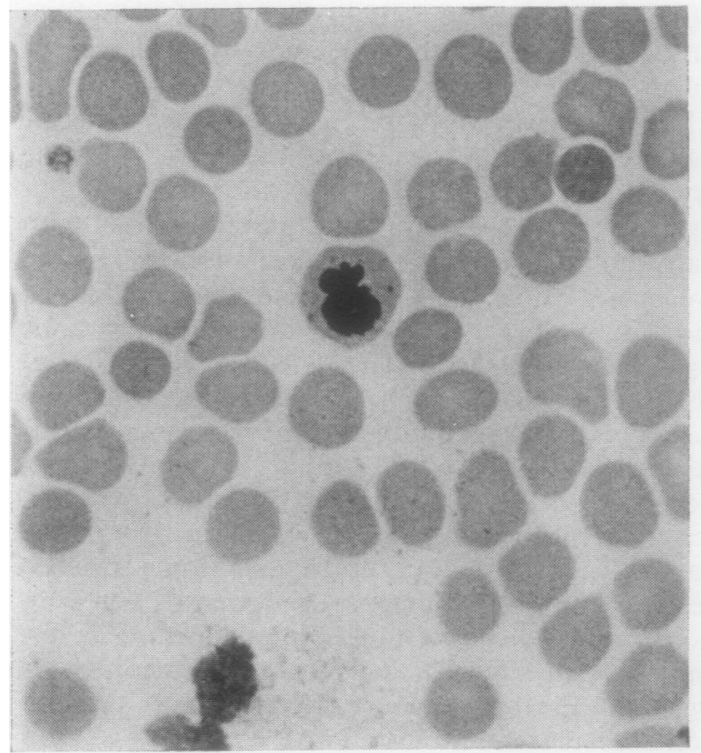

Fig 2c

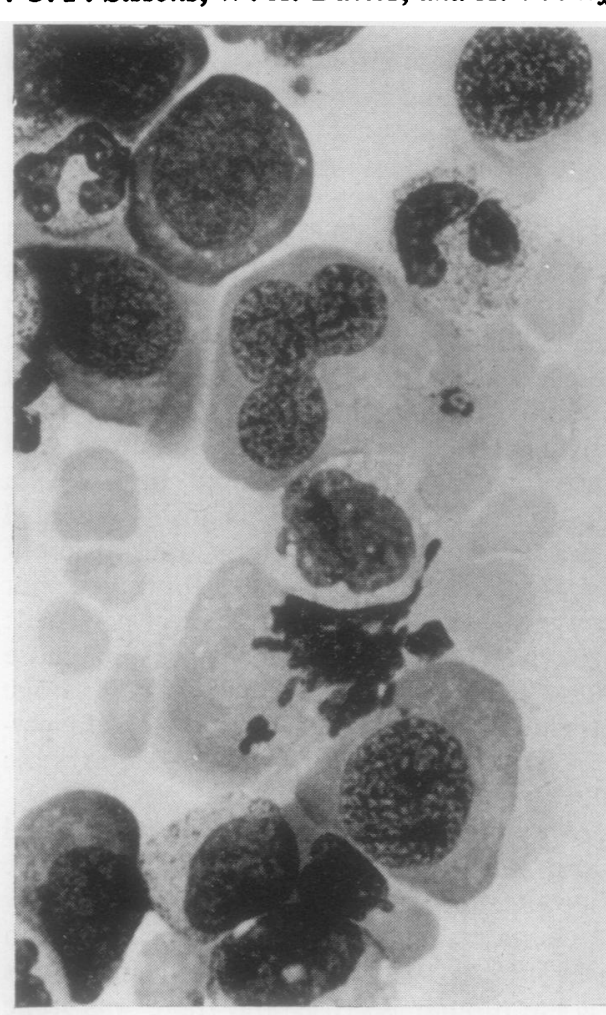

Fig 2d

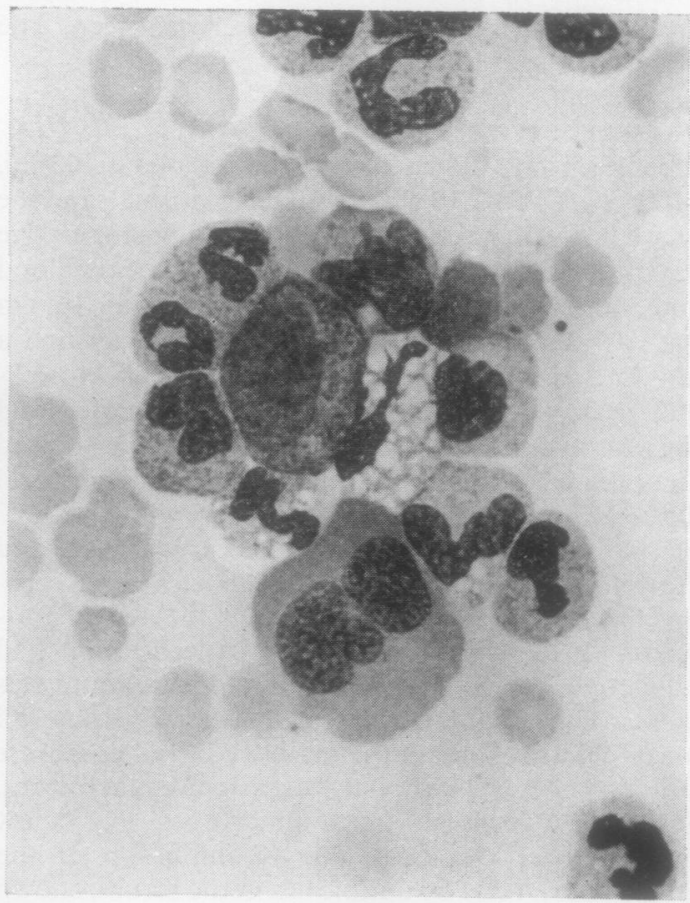

Fig 2e 


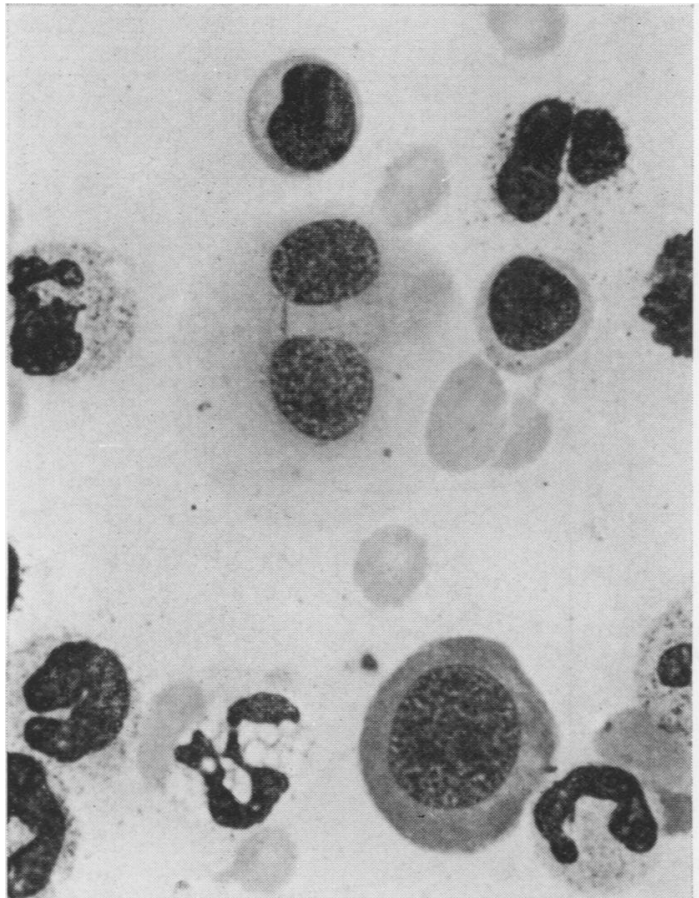

Fig $2 f$

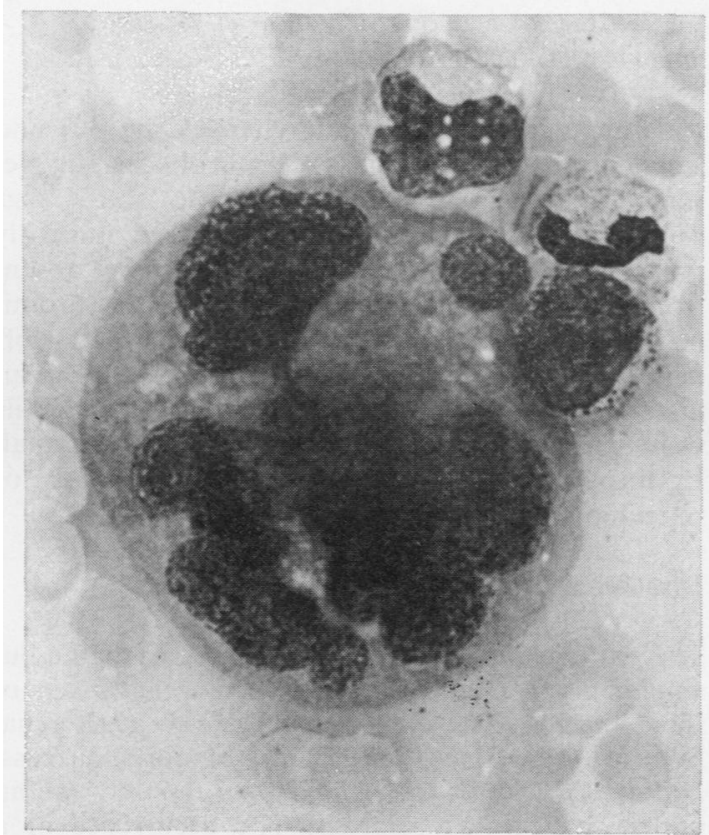

Fig $2 \mathrm{~g}$

Fig 2 Blood and bone marrow appearances in patient W.W. (case 1) $\times 1000$.
Case 2

This patient, D. W., a man aged 51 years, suffered myocardial infarction in 1966 and 1968. After the second of these a persisting pansystolic mitral murmur was noted. He also had an attack of gout in 1969. He remained well, apart from slight exertional dyspnoea, until 30 September 1972. He then developed a septic lesion on his left elbow, with fever and myalgia, and was treated with Amoxil (amoxycillin trihydrate) $250 \mathrm{mg}$ qds by his doctor; the symptoms did not improve and on 7 October he was admitted to Wexham Park Hospital (Dr P. Reed). He was febrile with small purple skin lesions on the soles of the feet; there was an apical pansystolic murmur and he was slightly confused with minimal neck stiffness. The haemoglobin was 11.4 $\mathrm{g} / 100 \mathrm{ml}$ and white cell count normal. The cerebrospinal fluid contained 190 polymorphs/cmm with normal CSF protein and sugar; no organisms were grown. He was treated with penicillin, chloramphenicol, and sulphadiazine but Staphylococcus aureus was isolated from eight blood cultures taken on admission. A diagnosis of staphylococcal septicaemia and endocarditis was made and he was treated with cloxacillin and fucidin. Initially his condition deteriorated and he developed further septic skin infarcts, but he then improved and the fever and abnormal neurological signs disappeared and the skin lesions healed. On 21 October he was transferred to Hammersmith Hospital for investigation of the cardiac lesion. On the basis of auscultation and the ultrasound recording he was thought to have mitral regurgitation due to papillary muscle dysfunction resulting from his previous infarct.

$\mathrm{He}$ continued to receive antibiotics and remained afebrile and well, apart from an acute attack of gout which responded to colchicine. On 12 November he returned to Wexham Park Hospital. Within two days he developed diarrhoea, pyrexia and became thrombocytopenic (platelets $91000 / \mu \mathrm{l}$ ) and leucopenic (WBC $3200 / \mu \mathrm{l}$ ); this was attributed to the colchicine therapy which was stopped. However, by 16 November he was confused and had evidence of intestinal bleeding, although coagulation tests showed no evidence of disseminated intravascular coagulation at this stage. Proteus vulgaris and $E$. coli were isolated from blood cultures and he was treated with gentamicin and ampicillin. He then became oliguric, his blood urea level rose, and on 22 November he was transferred back to Hammersmith Hospital.

Blood was oozing from venepuncture sites and he was jaundiced. The cardiac murmur was unchanged but the abdomen was distended with scanty bowel sounds and he was confused and drowsy although 
there were no focal neurological signs. Investigations showed: haemoglobin $10.8 \mathrm{~g} / 100 \mathrm{ml}$, white cell count $27000 / \mu \mathrm{l}$, plasma haemoglobin $138 \mathrm{mg} / 100 \mathrm{ml}$, serum fibrin-degradation products (FDP) titre 1 in 32 , blood urea $312 \mathrm{mg} / 100 \mathrm{ml}$. He was treated with combinations of carbenicillin, lincomycin, cephalothin, gentamicin, fucidin, parenteral vitamins, and folic acid $10 \mathrm{mg}$ daily intravenously; peritoneal dialysis was started. The serum vitamin $B_{12}$ was $344 \mathrm{pg} / \mathrm{ml}$, but serum folate assay was below the blank of the assay, presumably due to inhibition by antibiotics in the serum of the growth of $L$. casei.

By 26 November, his condition was unchanged; there was continued bleeding and further evidence of disseminate intravascular coagulation with platelets $63000 / \mu \mathrm{l}$, serum FDP $40 \mu \mathrm{g} / \mathrm{ml}$, and a prolonged partial thromboplastin-kaolin test (PTTK) and thrombinfibrinogen time, and heparin treatment was started. Over the next four days, uraemia was controlled by dialysis but the bleeding tendency and evidence of DIC persisted. The neurological signs were unchanged and he needed mechanical ventilation. He died on 30 November.

At necropsy the heart showed old infarction and healing with bacterial endocarditis on the mitral valve. There was evidence of bleeding into the gut and bronchial tree, the kidneys showed acute tubular necrosis, and the liver showed passive venous congestion. No extramedullary erythropoiesis was noted in the liver or spleen. The brain and coverings appeared normal.

\section{HAEMOTOLOGICAL FINDINGS}

Nucleated red cells were first observed in the peripheral blood on his second admission to Hammersmith Hospital on 23 November. At this time the haemoglobin was $10.8 \mathrm{~g} / 100 \mathrm{ml}$ with $2.7 \%$ reticulocytes and WBC $27000 / \mu$ l (fig 3). There was no macrocytosis on the film, the MCV being 88-90 fl. There were, however, megaloblasts, some with trilobed nuclei (fig 4a) and also erythroblasts with pyknotic nuclei. There was then a steady rise in numbers of circulating erythroblasts. These were megaloblastic for a few days (up to $600 / \mu \mathrm{l}$ ) but subsequently mainly normoblastic with striking dyserythropoietic changes (fig 4b), including binuclearity, nuclear budding, and basophilic stippling. There was a small but persistent rise in large myelocytes (up to $700 / \mu \mathrm{l}$ ), while the neutrophils showed a left shift though a few hypersegmented forms and an occasional 'macropolycyte' were also present (fig 4c).

Bone marrow aspiration was not carried out during life because of the severe bleeding disorder, but a sternal marrow aspiration was performed an hour after death. The marrow was normocellular with
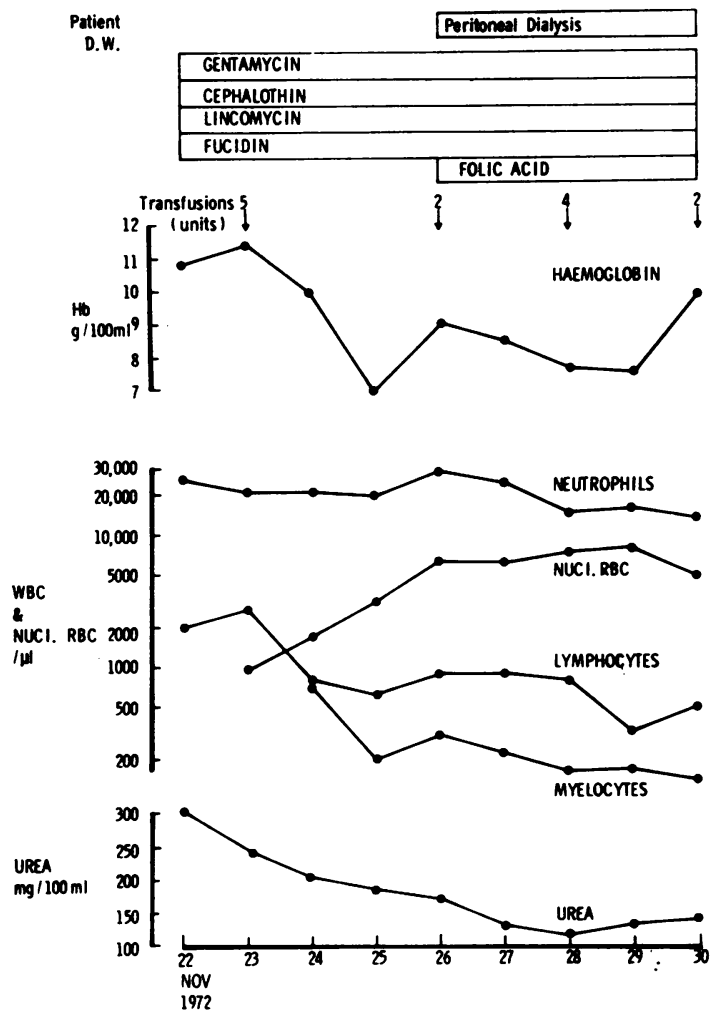

Fig 3 Haematology chart of patient D. W. (case 2) in the terminal phase of his illness.

widespread dyserythropoietic changes (fig 4d) and isolated clusters of large proerythroblasts (fig 4e) some of which had long cytoplasmic 'spurs' (figs 4f and 4g). Erythropoiesis was predominantly normoblastic. Iron was present in stores but absent from erythroblasts. Granulopoiesis was less prominent than erythropoiesis, and showed a left shift with a predominance of promyelocytes. A few giant metamyelocytes and hypersegmented neutrophils were present. Megakaryocytes appeared normal. Erythrophagocytosis was seen in a number of reticulum cells.

\section{Discussion}

The patients described here showed remarkable but $\stackrel{\varrho}{\subset}$ similar blood pictures during the terminal phase of $\mathbb{\Phi}$ their illnesses. They both suffered from acute renal failure, unexplained disturbance of consciousness, and overwhelming infection superimposed on an underlying cardiac disorder. The occurrence of a leucoerythroblastic blood picture in severely ill $\stackrel{\mathbb{Q}}{\circ}$ patients is well known. It has been described in congestive heart failure, severe infections, and liver 


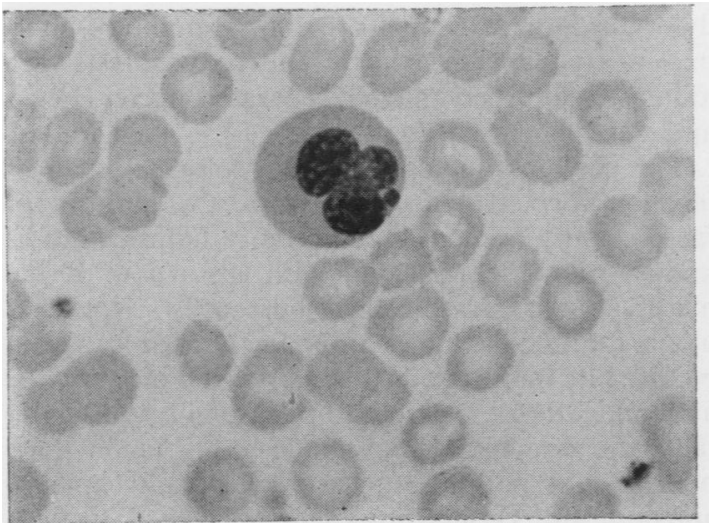

Fig $4 \mathrm{a}$

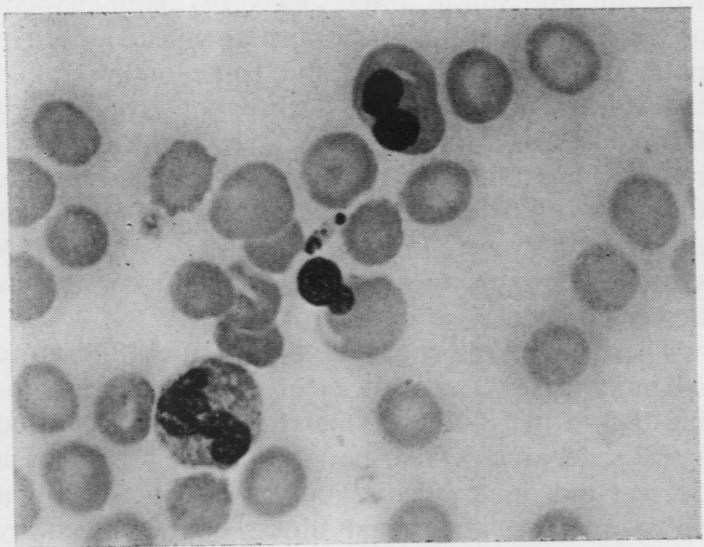

Fig $4 b$

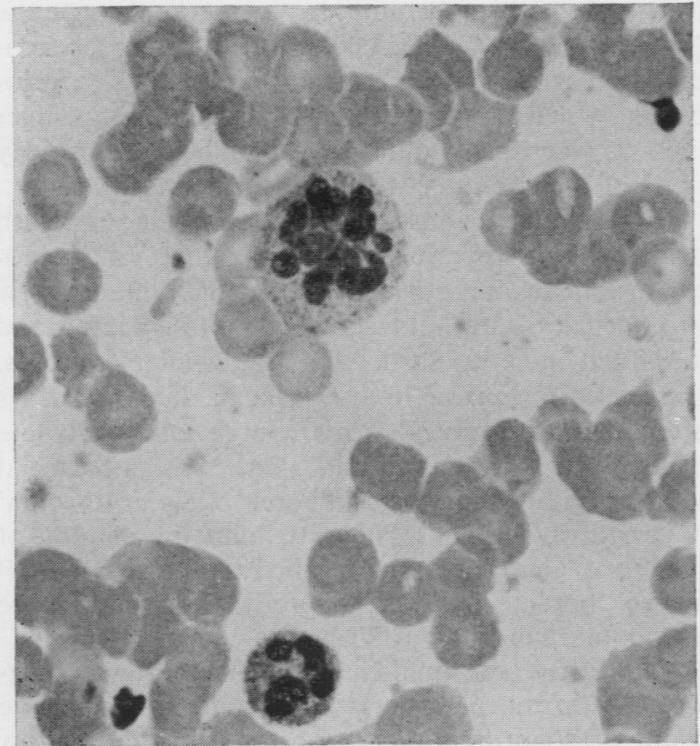

Fig 4c

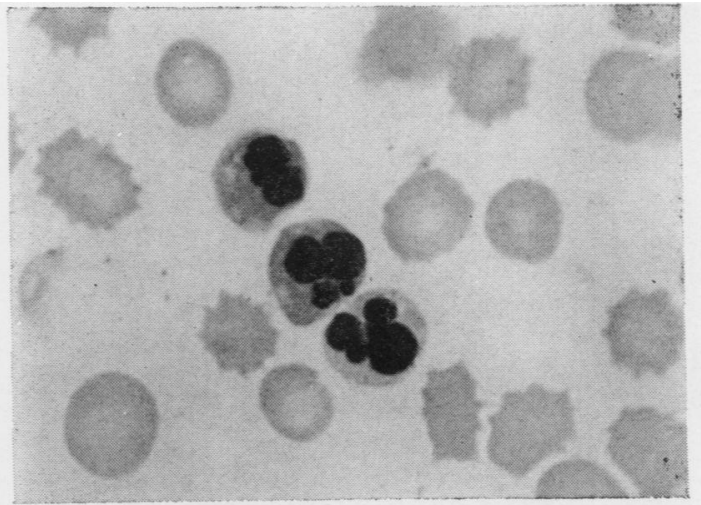

Fig 4d

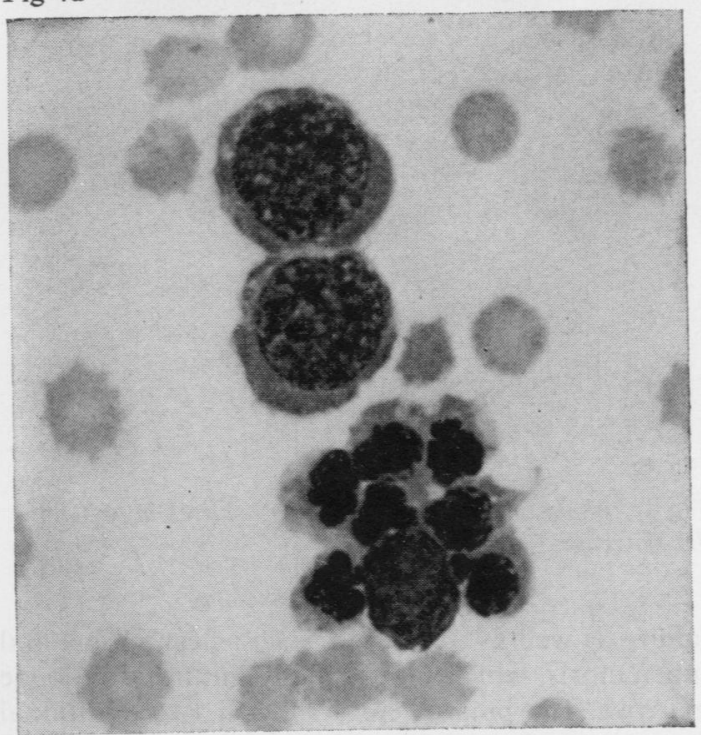

Fig $4 \mathrm{e}$

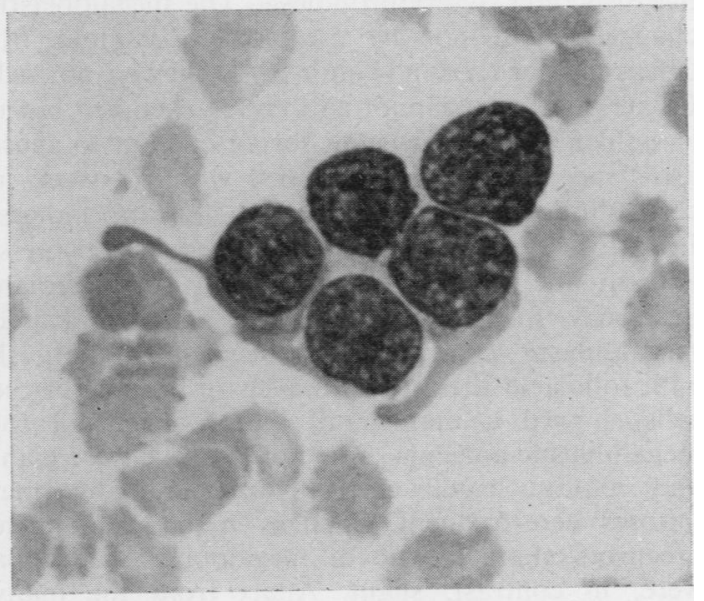

Fig $4 f$ 


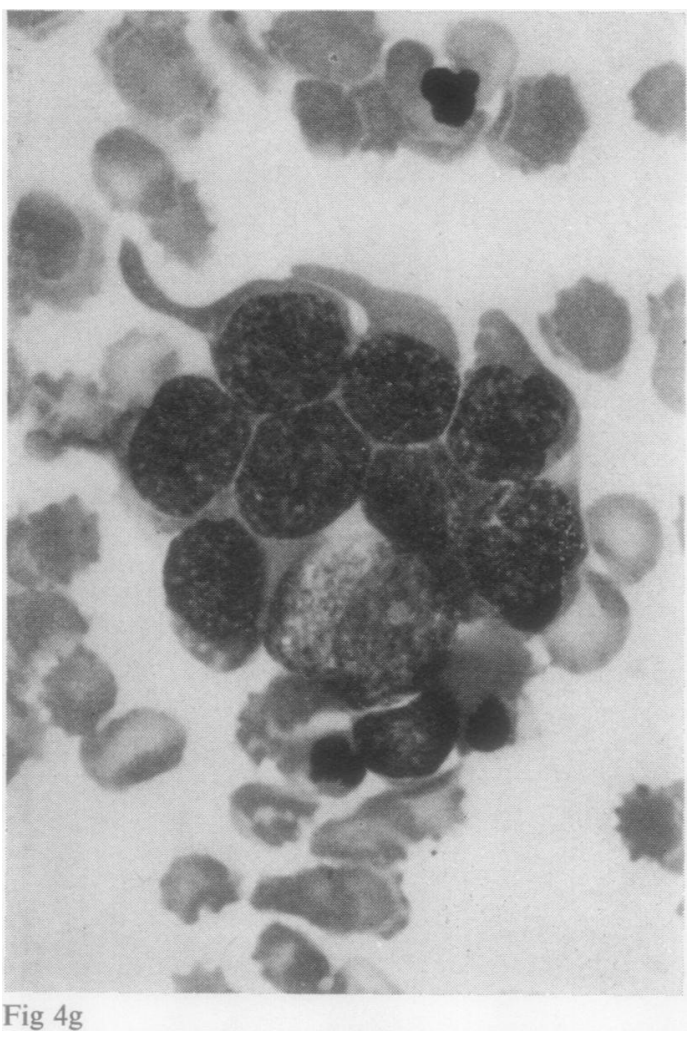

Fig 4 Blood and bone marrow appearances in patient D. W. (case 2) $\times 1000$.

failure as well as in diseases such as carcinoma and tuberculosis, which may actually infiltrate the bone marrow. The present cases showed two additional features to leucoerythroblastic anaemia, megaloblastosis, and dyserythropoiesis. The megaloblastic changes could not be ascribed to vitamin $B_{12}$ deficiency since serum vitamin $B_{12}$ levels were normal. Folate deficiency cannot entirely be excluded but it is unlikely that deficiency severe enough to cause gross megaloblastosis developed within a week in case 1 following a normal blood film and indices. In case 2, there was a more prolonged severe illness, and in the presence of infection severe folate deficiency may have developed and aggravated megaloblastic changes which seemed to diminish with folic acid therapy. However, in both cases the cells showed a number of features unusual for megaloblastic anaemia. Some of the cells were giant and multinucleated erythroblasts and abnormal mitoses were frequent. Changes in the granulocyte precusors characteristic of megaloblastic anaemia were, in contrast, slight. Apart from the many multinucleated cells present, other evidence of gross dyserythropoiesis was present including internuclear stands, karyorrhexis, and erythroblasts with lobulated and incompletely separated nuclei (Lewis and Verwilghen, 1947).

The explanation for the haematological changes in these two patients is obscure. A number of factors must be considered. Renal failure itself is known to cause anaemia, with distortion of the mature red cells-so-called 'burr cells'. However, uraemia alone has not, to our knowledge, caused a picture like that described here. Anoxia may well be a stimulus to the marrow to release normoblasts to the peripheral blood, but the arterial $\mathrm{pO}_{2}$ in these patients did not fall for any substantial time to anoxic levels. Dyserythropoietic changes have been described before in patients with infections (Dreyfus, Rochant, and Sultan, 1969; Lewis, 1972) but changes as gross as those found here must be unusual, even in patients with septicaemia and some other special factor must be concerned. Both patients were given large doses of antibiotics which, in the presence of renal failure, may well have accumulated in the blood stream to give high levels. None of the drugs used are, however, known to interfere with DNA synthesis or to produce dyserythropoietic changes as described here.

There have been sporadic reports in the literature of similar cases. The presence of multilobed gigantoblasts in a megaloblastic marrow was first reported by Harvier and Mallarme (1938). Their patient, a 51-year-old male alcoholic was in the terminal episode of an abdominal illness characterized by vomiting, weight loss, hepatomegaly, skin pigmentation, and systolic murmur. He was markedly anaemic (Hb $30 \%$, RBC $700000 / \mathrm{cmm}$ ) with a lecucoerythroblastic picture featuring circulating megaloblasts, which was unaffected by large doses of liver extract. Necropsy did not reveal cirrhosis. Curiously none of the subsequent reports mention this paper.

Limarzi and Levinson (1943) describe a man with urinary tract infection whose anaemia was leucoerythroblastic and normocytic, yet the bone marrow was megaloblastic and showed multinucleated and lobulated gigantoblasts and multipolar mitoses. Despite injections of liver extract he died three days after prostatectomy. The marrow revealed only late pyknotic erythroblasts, and there was substantial infiltration by primitive cells resembling 'erythroma' of 'erythroblastoma'. They attribute the coining of the term, 'gigantoblast' to Ehrlich and Lazarus (1909) whose book, however, merely described large megaloblasts as gigantoblasts.

Two further terminal cases of anaemia with megaloblasts in the peripheral blood and multinucleate 'giant orthochromatic erythroblasts' in the marrow are recorded by Schleicher (1944). Berman (1947) 
described eight patients with mainly haematological disorders who apparently had 'plurinuclear erythroblasts in the marrow; only one was megaloblastic and none of the patients died. Finally, Lonser and Hadley (1955) report on a man of 58 who had a long history of exfoliative dermatitis and was irradiated with a total of $6150 \mathrm{r}$. Terminally he developed a severe macrocytic anaemia which was unresponsive to 'vigorous antipernicious anaemia therapy'. The bone marrow showed 'multipolar giant erythroblasts', some with bizarre nuclear configuration similar to the case of Limarzi and Levinson and the first case reported here.

At present, we describe a further two cases of this clinical and haematological syndrome without knowing its exact cause. Studies of DNA synthesis and other aspects of erythropoiesis in future cases may, however, help to elucidate the mechanism of this unusual disturbance of erythropoiesis.

We are grateful to Dr P. Reed, Dr D. K. Peters, and Professor H. Bentall for permission to publish these cases and to Professor D. L. Mollin and Dr J. F. Burman for helpful discussion on the earlier literature. We also wish to thank Mr W. F. Hinkes for the photomicrographs.

References

Berman, L. (1947). The clinical significance of cellular gigantism in human erythropoiesis. J. Lab. clin. Med., 32, 793-806.

Chanarin, I. (1969). The Megaloblastic Anaemias, pp. 308-319. Blackwell, Oxford.

Dreyfus, B., Rochant, H., and Sultan, C. (1969). Anémies réfractaires: enzymopathies acquises des cellules souches hématoplétiques. Nouv. Rev. frac. Hémat., 9, 65-85.

Ehrlich, P., and Lazarus, A. (1910). Anaemia, translated by H. W. Armit, 2nd ed., Pt. 1, Vol. 1, pp. 69-70. Rebman, London.

Harvier, P., and Mallarme, J. (1968). Maladie de biermer à forme hépatomégalique avec pigmentation, simulant une cirrhose pigmentaire. Sang, 12, 883-886.

Hoffbrand, A. V. (1971). The megaloblastic anaemias. In Recent Advances in Haematology, edited by $\mathbf{A}$. Goldberg and $\mathbf{M}$. C. Brian, pp. 1-76. Churchill Livingstone, and Edinburgh London.

Lewis, S. M. (1972). Dysplastic anaemias. Nouv. rev. franc. Hémat., $12,375-383$.

Lewis, S. M., and Verwilghen, R. L. (1974). Dyserythropoiesis and dyserythropoietic anemia. Progr. Hemat., 8, 99-129.

Limarzi, L. R., and Levinson, S. A. (1943). An undescribed type of erythropoiesis observed in human sternal marrow. Arch. Path., 36, $127-143$.

Lonser, E. R., and Hadley, G. G. (1955). Multipolar giant erythroblastosis (A second observation). Rev. belge Path., 24, 389-394.

Schleicher, E. M. (1944). Giant orthochromatic erythroblasts. J. Lab. clin. Med., 29, 127-133. 